\title{
Animasi Interaktif Klasifikasi Jangkauan Dan Topologi Jaringan Komputer Berbasis Android Sebagai Media Belajar
}

\author{
Muhammad Rezki ${ }^{1}$, Muhammad Ifan Rifani Ihsan², Diah Ayu Ambarsari ${ }^{3}$ \\ ${ }^{1}$ Program Studi Teknik Informatika, Fakultas Teknologi Informasi, Universitas Nusa Mandiri \\ Jl. Raya Jatiwaringin, Cipinang Melayu, Makasar, Jakarta Timut-13630, Indonesia \\ ${ }^{2}$ Program Studi Sains Data, Fakultas Teknologi Informasi, Universitas Nusa Mandiri \\ Jl. Raya Jatiwaringin, Cipinang Melayu, Makasar, Jakarta Timut-13630, Indonesia \\ ${ }^{3}$ Program Studi Sistem Informasi, Fakultas Teknologi Informasi, Universitas Nusa Mandiri \\ Jl. Raya Jatiwaringin, Cipinang Melayu, Makasar, Jakarta Timut-13630, Indonesia \\ e-mail: ${ }^{1}$ Muhammad.mdk@ nusamandiri.ac.id, ${ }^{2}$ ifan.mii @ nusamandiri.ac.id, ${ }^{3}$ Diah.das@ nusamandiri.ac.id
}

Artikel Info : Diterima : 04-07-2021 | Direvisi : 11-07-2021 | Disetujui : 19-07-2021

\begin{abstract}
Abstrak - Klasifikasi jangkauan dan topologi memiliki jenis dan karakteristik tersendiri. Banyaknya jenis klasifikasi jangkuan dan topologi, serta metode proses dalam pembelajaran di sekolah yang kurang interaktif sehingga siswa jenuh dalam proses belajar, terutama bagi siswa SMK Jurusan Teknik Komputer dan Jaringan. Dalam praktiknya, yaitu membuat kabel LAN membutuhkan peralatan yang cukup mahal sehingga sulit untuk melakukan kegiatan praktik tersebut diluar sekolah. Sehingga siswa sulit mengembangkan kemampuannya terutama dibidang kejuruan tersebut. Dengan perkembangan teknologi saat ini tentu saja dapat dimanfaatkan dalam dunia pendidikan, salah satu pemanfaatannya yaitu dengan membuat aplikasi edukasi yang dapat memberikan suasana baru dalam belajar. Animasi interaktif dapat menjadi solusi dalam mengatasi masalah praktek membuat kabel LAN dan penjelasan tentang Topologi Jaringan. Animasi interaktif ini dibuat dengan menggunakan software Construct 2, dikembangkan dengan metode pengembangan multimedia serta teknik pengumpulan data berupa observasi, wawancara dan studi pustaka. Tujuan dari pembuatan aplikasi interaktif adalah agar siswa bisa memahami klasifikasi jangkauan dan topologi dengan baik, serta bisa mempraktikkan memasang kabel LAN melalui software animasi interaktif simulasi sebagai pengganti fasilitas sekolah.
\end{abstract}

Kata Kunci : Construct 2, Animasi Interaktif, Jaringan Komputer

Abstracts - Classification of range and topology has its own types and characteristics. There are many types of outreach classifications and topologies, as well as process methods in learning in schools that are less interactive so that students are bored in the learning process, especially for students of SMK Computer and Network Engineering Department. In practice, making LAN cables requires equipment that is quite expensive, making it difficult to carry out these practical activities outside of school. So that students find it difficult to develop their abilities, especially in the vocational field. With current technological developments, of course, it can be used in the world of education, one of the uses is by making educational applications that can provide a new atmosphere in learning. Interactive animation can be a solution in overcoming the practice of making LAN cables and an explanation of Network Topology. This interactive animation was made using Construct 2 software, developed using multimedia development methods and data collection techniques in the form of observations, interviews and literature studies. The purpose of making interactive applications is so that students can understand the range classification and topology well, and can practice installing LAN cables through interactive animation simulation software as a substitute for school facilities.

Keywords : Construct 2, Interactive Animation, Computer Networks

\section{PENDAHULUAN}

Dalam dunia pendidikan, komputer termasuk mata pelajaran disekolah. Klasifikasi jangkauan dan topologi jaringan adalah salah satu materi pelajaran yang ada pada sekolah menengah kejuruan (SMK). Teknik Komputer \& Jaringan (TKJ) merupakan salah satu jurusan yang berhubungan dengan kemampuan pemrograman komputer, perakitan komputer dan jaringan komputer dan pengoperasian perangkat lunak komputer. Dengan 
hal tersebut SMK dapat mengembangkan pendidikan sebagai kemampuan siswa-siswi yang sesuai jurusan yang telah diambil (Kusumayanti \& Astuti, 2021).

Klasifikasi jangkauan dan topologi jaringan komputer ini memiliki banyak jenis dan perbedaan masingmasing. Siswa harus terlebih dahulu mempelajari tentang klasifikasi dan topologi jaringan sebelum mengimplementasikannya. Banyaknya jenis klasifikasi jangkauan dan topologi inilah yang menyulitkan meteri ini sulit untuk dikuasai. Dalam praktiknya membuat kabel LAN membutuhkan peralatan yang cukup mahal membuat siswa sulit melakukan kegiatan praktik tersebut diluar sekolah. Mengakibatkan siswa sulit mengembangkan kemampuannya. Dengan perkembangan teknologi saat ini tentu saja dapat dimanfaatkan dalam dunia pendidikan, salah satu pemanfaatannya yaitu dengan membuat aplikasi edukasi yang dapat memberikan suasana baru dalam belajar. Animasi interaktif ini dapat menjadi pemecah masalah siswa dalam praktek membuat kabel LAN dan penjelasan tentang Topologi Jaringan. Animasi interaktif ini dibuat dengan menggunakan software Construct 2.

Construct2 adalah aplikasi pembuat game ciptaan Scirra yaitu salah satu yang diminati oleh para game developer karena construct 2 yang mudah digunakan dan memiliki banyak tutorial serta template yang telah tersedia. Android adalah salah satu device dari construct2 menggunakan HTML5 (Damayanti et al., 2020). Construct 2 yaitu salah satu software yang dapat membuat aplikasi atau game (game engine), pemilihan software Construct 2 memiliki alasan karena mudah memahami sebuah materi jika disampaikan dengan menarik dan unik serta tidak memerlukan pemprograman yang rumit untuk membuatnya (Herawati et al., 2018).

Penggunaan animasi interaktif adalah solusi terbaik dalam memecahkan masalah yang ada, selain dapat digunakan untuk media pembelajaran, animasi interaktif juga dapat menghilangkan jenuh terhadap aktivitas anak sehari-hari (Saputra \& Retnoningsih, 2020). Media pembelajaran interaktif ini akan lebih jelas, lengkap, dan menarik bagi siswa-siswi. Media pembelajaran interaktif juga dapat menyediakan materi yang dapat membangkitkan antusiasme siswa dalam belajar, merangsang siswa untuk bereaksi secara fisik dan emosional, sehingga dapat meningkatkan semangat siswa-siswi dalam proses belajar (Haris \& Putra, 2020).

Tujuan dari pembuatan animasi aplikasi interaktif adalah agar siswa bisa memahami tentang klasifikasi jangkauan dan topologi dengan baik, serta bisa mempraktikkan memasang kabel LAN melalui software animasi interaktif simulasi sebagai pengganti fasilitas sekolah.

Media merupakan sebuah alat bantu yang telah digunakan oleh dunia pendidikan dalam proses pembelajaran (Luhulima et al., 2017).

Multimedia adalah media pembelajaran yang terdiri dari beberapa elemen media yang dipresentasikan dalam media komputer. Multimedia interaktif adalah solusi untuk siswa mempelajari materi yang lebih mudah dibandingkan dengan buku teks/e-book yang kaku dan membosankan (Armansyah et al., 2019).

Android yaitu sistem operasi yang dikembangkan untuk piranti mobile berbasis Linux. Pada awalnya sistem operasi ini dikembangkan oleh Android Inc. yang kemudian diakuisisi oleh Google pada tahun 2005 (Maiyana, 2018). Android yaitu salah satu sistem operasi mobile yang tumbuh di tengah sistem operasi lain yang berkembang saat ini. Android yaitu platform komprehensif bersifat sumber terbuka yang dibuat untuk perangkat mobile. Android merupakan sistem operasi berbasis Linux yang diperuntukkan untuk mobile device (Nurhalimah et al., 2017).

\section{METODE PENELITIAN}

Dalam peneltian ini, dilakukan pengumpulan data dengan beberapa cara, diantaranya sebagai berikut:

1. Observasi

Kegiatan yang dilakukan untuk mendapatkan data yang berhubungan dengan permasalahan yang diambil dengan cara melakukan pengamatan langsung terhadap kegiatan belajar mengajar.

2. Wawancara

Untuk mendapatkan informasi secara lengkap maka peneliti melakukan tanya jawab dengan beberapa siswa dan guru pendidik guna mendapatkan data yang tepat.

3. Studi Pustaka

Peneliti melakukan studi pustaka dengan mencari beberapa literatur seperti buku, jurnal, artikel, dan sumbersumber lain dari internet yang berhubungan dengan pembahasan yang diambil, kemudian dijadikan sebuah referensi.

Terdapat 5 tahapan penelitian:

1. Analisis kebutuhan

Tahap ini adalah langkah awal untuk menentukan konsep dasar dalam perancangan aplikasi yang akan dirancang. Pada tahap ini dilakukan identifikasi kebutuhan pengguna, jenis aplikasi, tujuan aplikasi dan spesifikasi umum.

2. Desain

Desain adalah tahap selanjutnya yang dilakukan untuk merancang spesifikasi secara detail tentang rancangan dan kebutuhan pengembangan multimedia. Pada tahap ini dibuat rancangan flowchart view dan storyboard, tampilan pada setiap aplikasi yang ingin dibangun.

3. Code generation

Pada tahap code generation ini dilakukan proses translasi hasil dari tahap desain ke tahap selanjutnya. Pada tahap ini peneliti tidak menggunakan bahasa pemrograman khusus, karena semua syntak yang digunakan pada 
game disetting dalam evenSheet yang terdiri dari event dan Action.

4. Testing

Tahap ini yaitu tahap pengujian aplikasi yang telah selesai dibuat untuk mengetahui jika terdapat kesalahan atau error. Untuk testing peneliti menggunakan metode whitebox testing.

5. Support

Pada tahap ini adalah proses publikasi aplikasi yang dibuat disimpan ke dalam sebuah media dan sudah siap untuk di operasikan atau dijalankan.

\section{PEMBAHASAN}

1. Desain

Sebelum animasi diimplementasikan kedalam bentuk program, maka perlu dirancang terlebih dahulu. Tahap perancangan memiliki tujuan untuk memenuhi kebutuhan pengguna dan memberikan gambaran yang jelas terhadap program animasi ini.

A. Perancangan Storyboard

Storyboard merupakan penggambaran alur cerita dari sebuah animasi dan berisi tentang pengambilan sudut gambar, pengisian suara, serta efek-efek khusus yang ada pada animasi. Fungsi Storyboard adalah mengartikan isi dari skenario secara visual atau penggambaran secara singkat (Rosmaidah \& Destiana, 2017). Berikut ini adalah rancangan storyboard animasi interaktif ini:

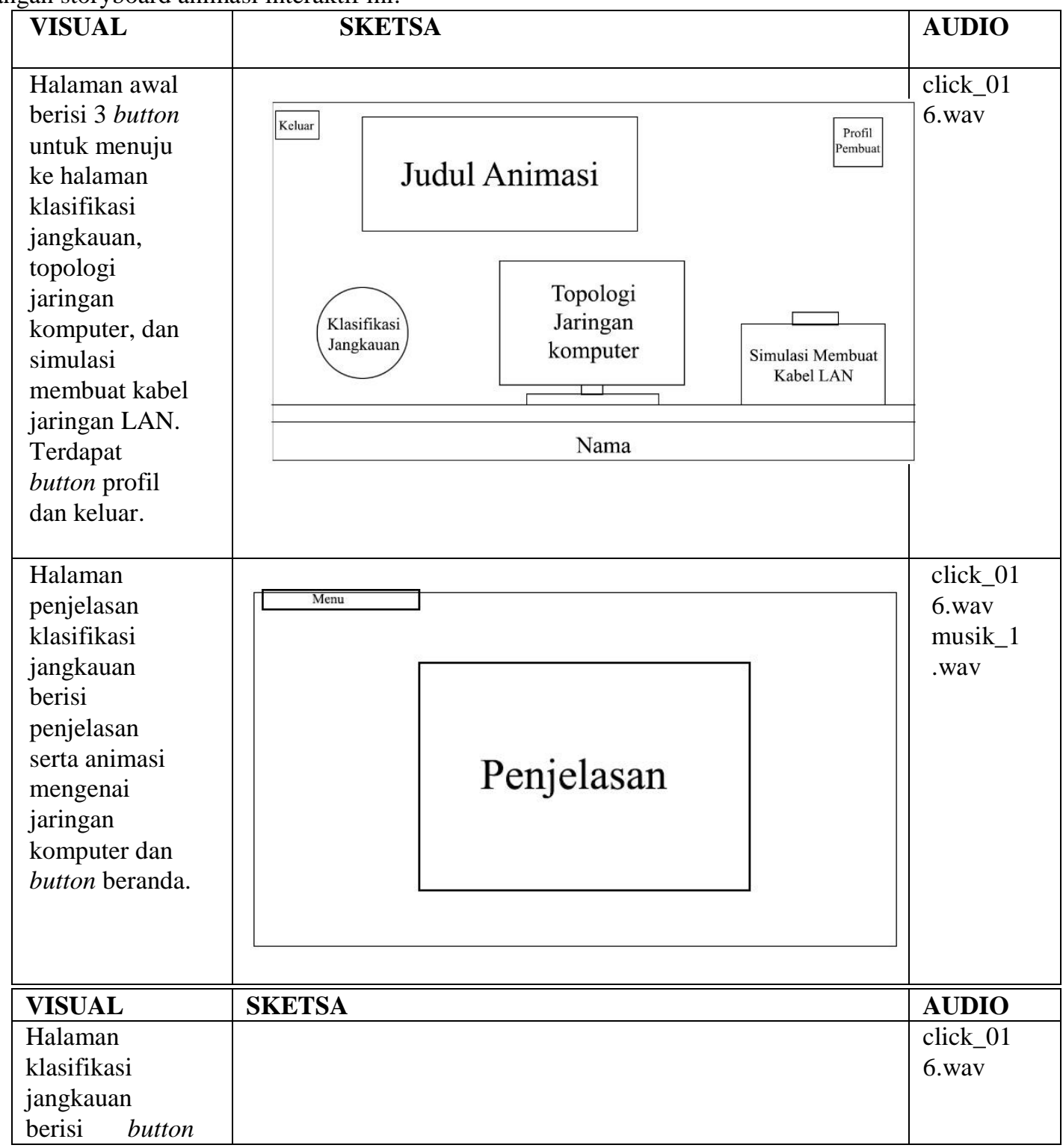




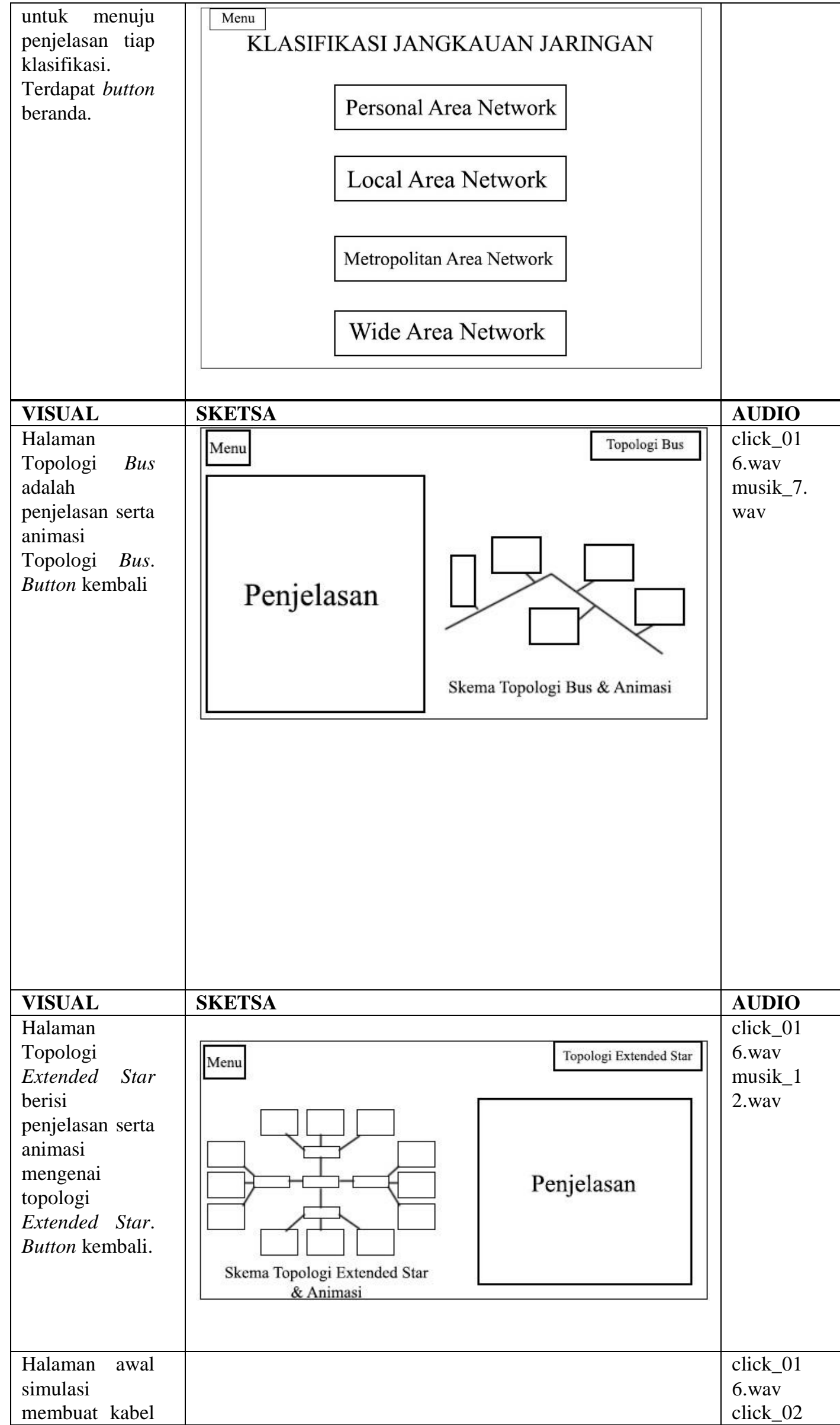


Computer Science (CO-SCIENCE)

Volume 1 No. 2 Juli 2021 | E-ISSN: 2774-9711

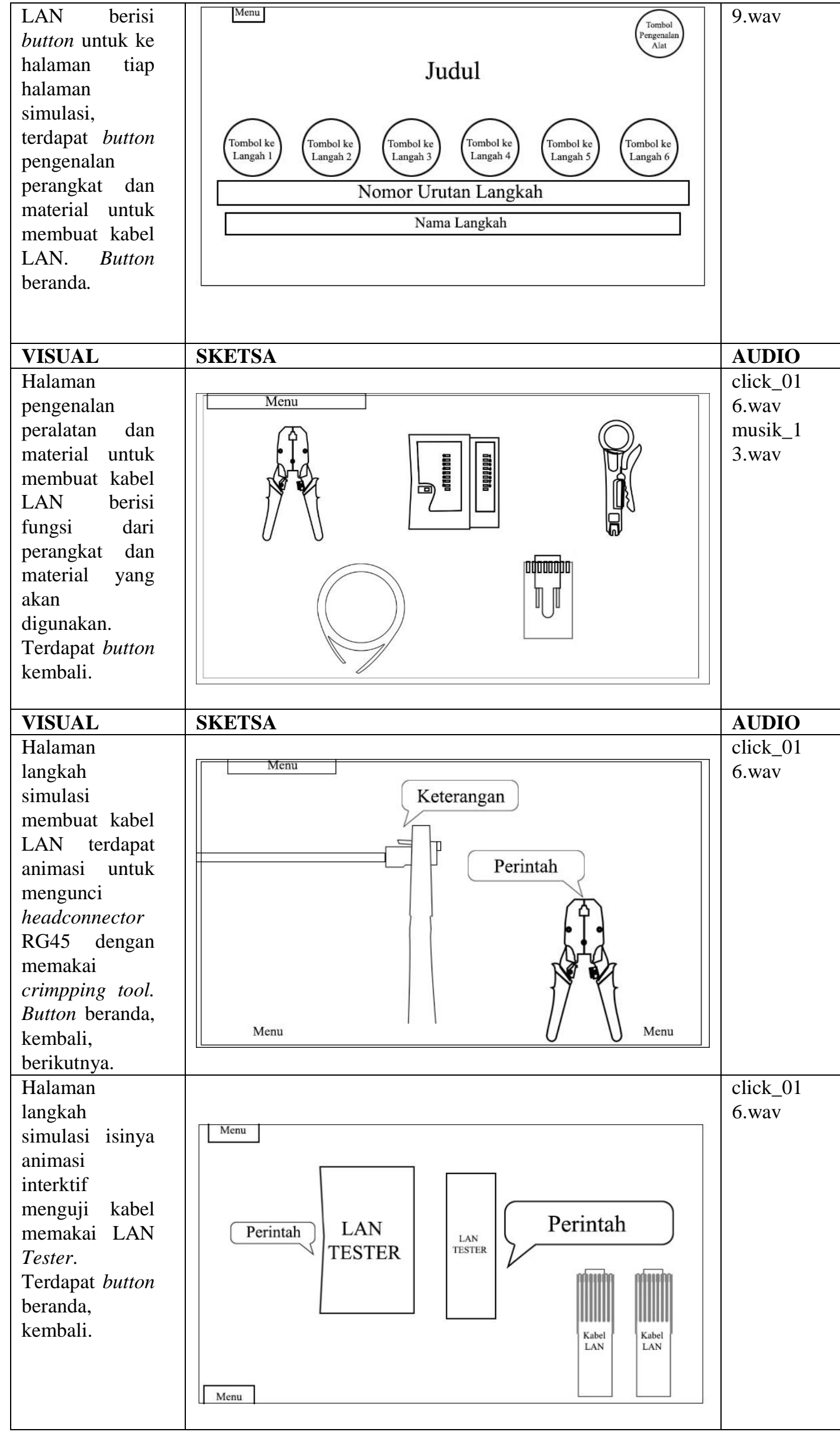


2. User Interface

Tabel 1. Desain Storyboard

Rancangan antarmuka merupakan rancangan awal aplikasi yang akan dibuat, rancangan antarmuka animasi interaktif sebagai media belajar pengenalan klasifikasi jangkauan dan topologi jaringan komputer yaitu:

A. Antarmuka Halaman Awal Aplikasi

Halaman awal software, berisi 3 button untuk menuju ke halaman penjelasan klasifikasi jangkauan, topologi jaringan komputer, dan praktik membuat kabel jaringan LAN. Ada button keluar dan profil pembuat.

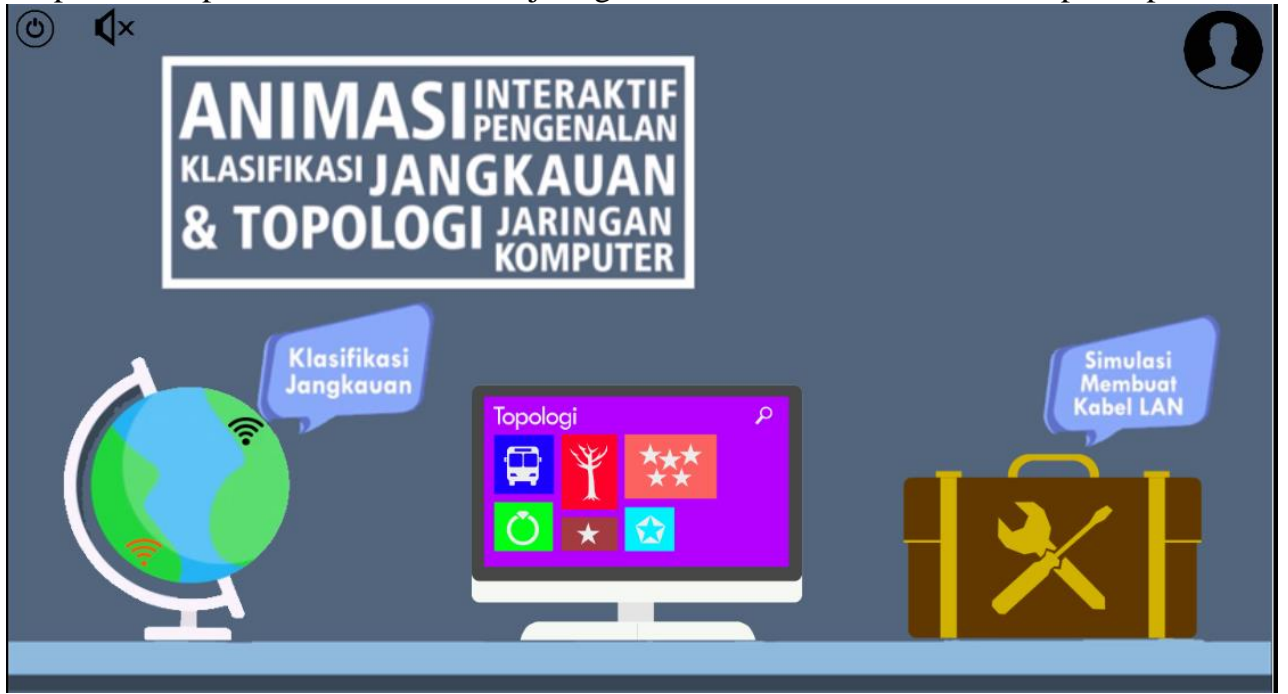

Gambar 1. Antarmuka Halaman Awal Aplikasi

B. Antarmuka Halaman Klasifikasi Jangkauan

Antarmuka halaman Klasifikasi Jangkauan berisi menu jangkauan jaringan dan button home.

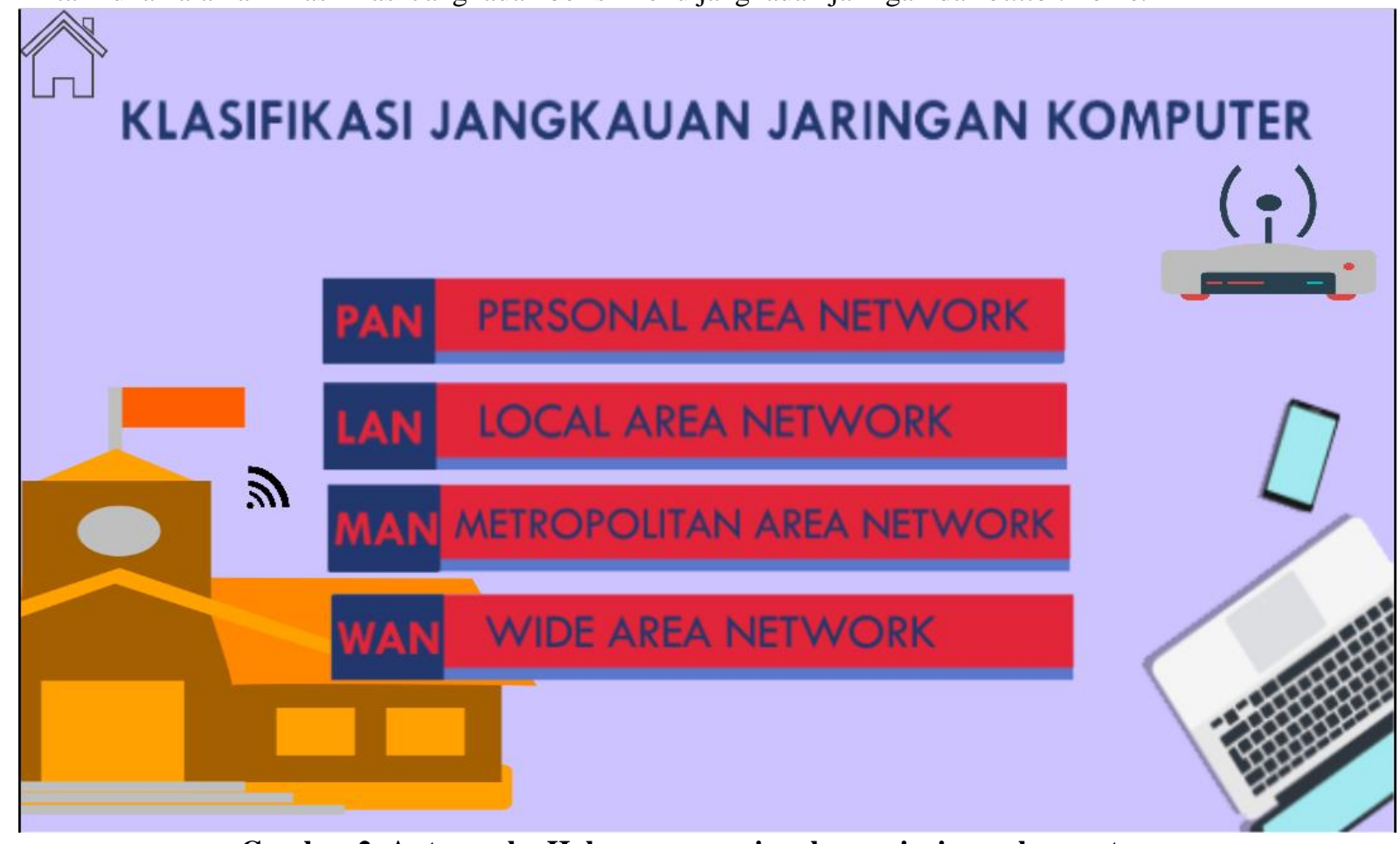

Gambar 2. Antarmuka Halaman menu jangkauan jaringan komputer

C. Rancangan Antarmuka Intro Topologi

Antarmuka halaman penjelasan Topologi berisi penjelasan tentang topologi. Terdapat pilihan topologi dan button home untuk menuju ke menu utama. 


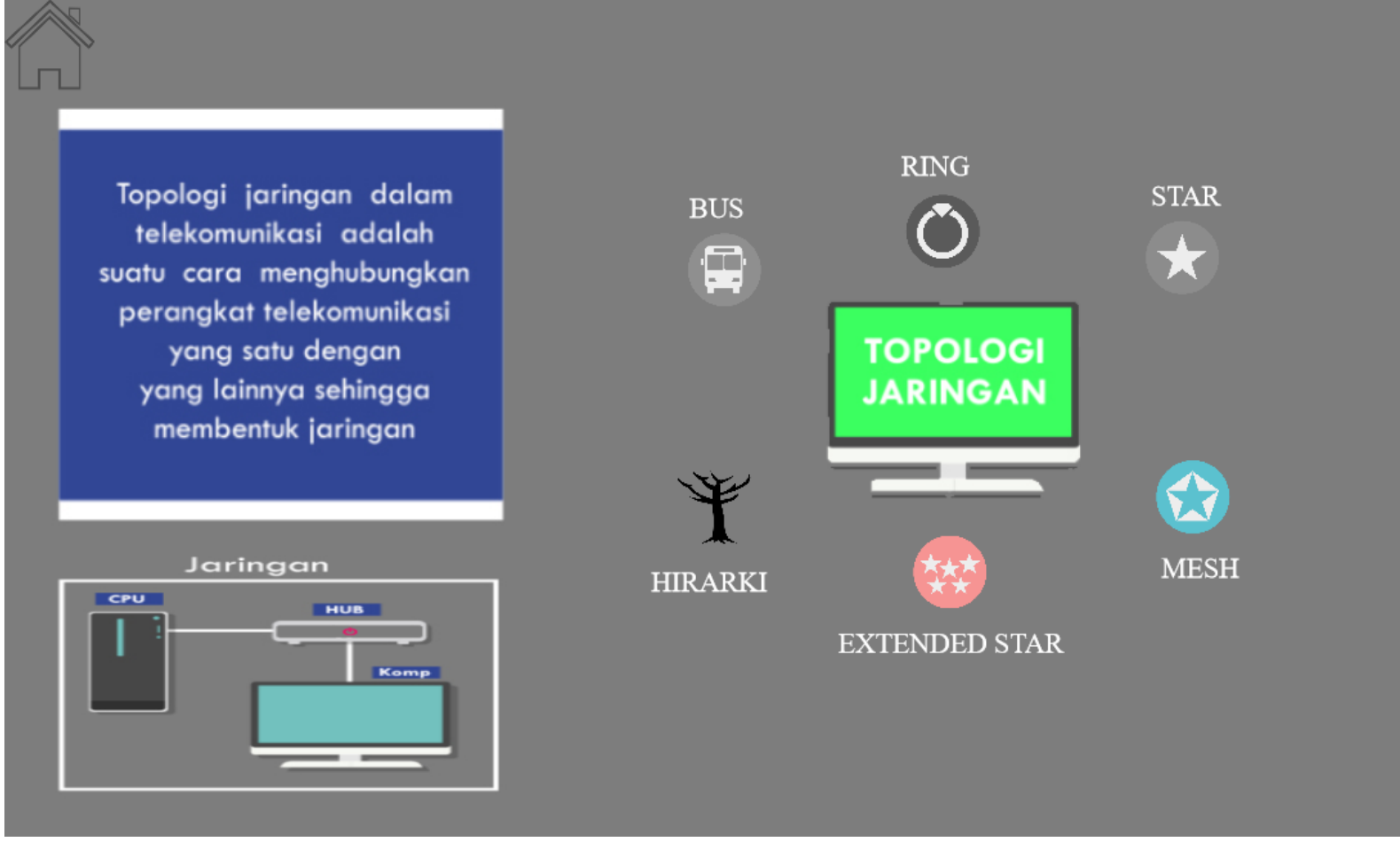

D. Antarmuka Halaman topologi BUS

\section{Gambar 3. Antarmuka Halaman Intro Topologi}

Antarmuka halaman Pilihan Topologi BUS berisi animasi topologi BUS, terdapat button kembali ke menu sebelumnya.

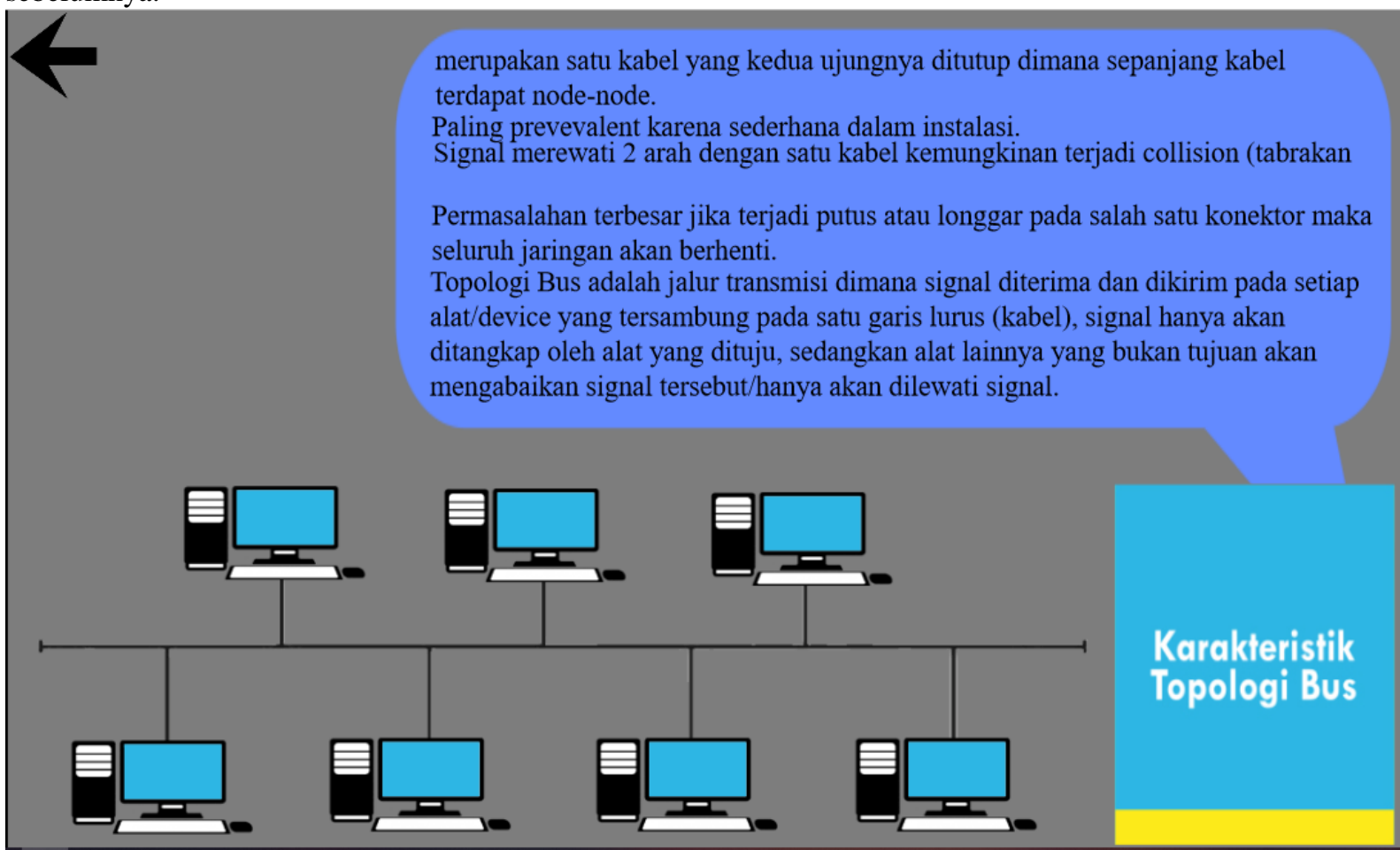

Gambar 4. Antarmuka Halaman Pilihan Topologi

E. Antarmuka Urutan Simulasi Membuat Kabel LAN dan button masuk ke menu Alat dan bahan

Antarmuka urutan praktik membuat kabel LAN berisi button untuk ke halaman tiap-tiap halaman praktik, terdapat button pengenalan alat dan button masuk ke menu Alat dan bahan serta material untuk membuat kabel LAN serta button beranda. 


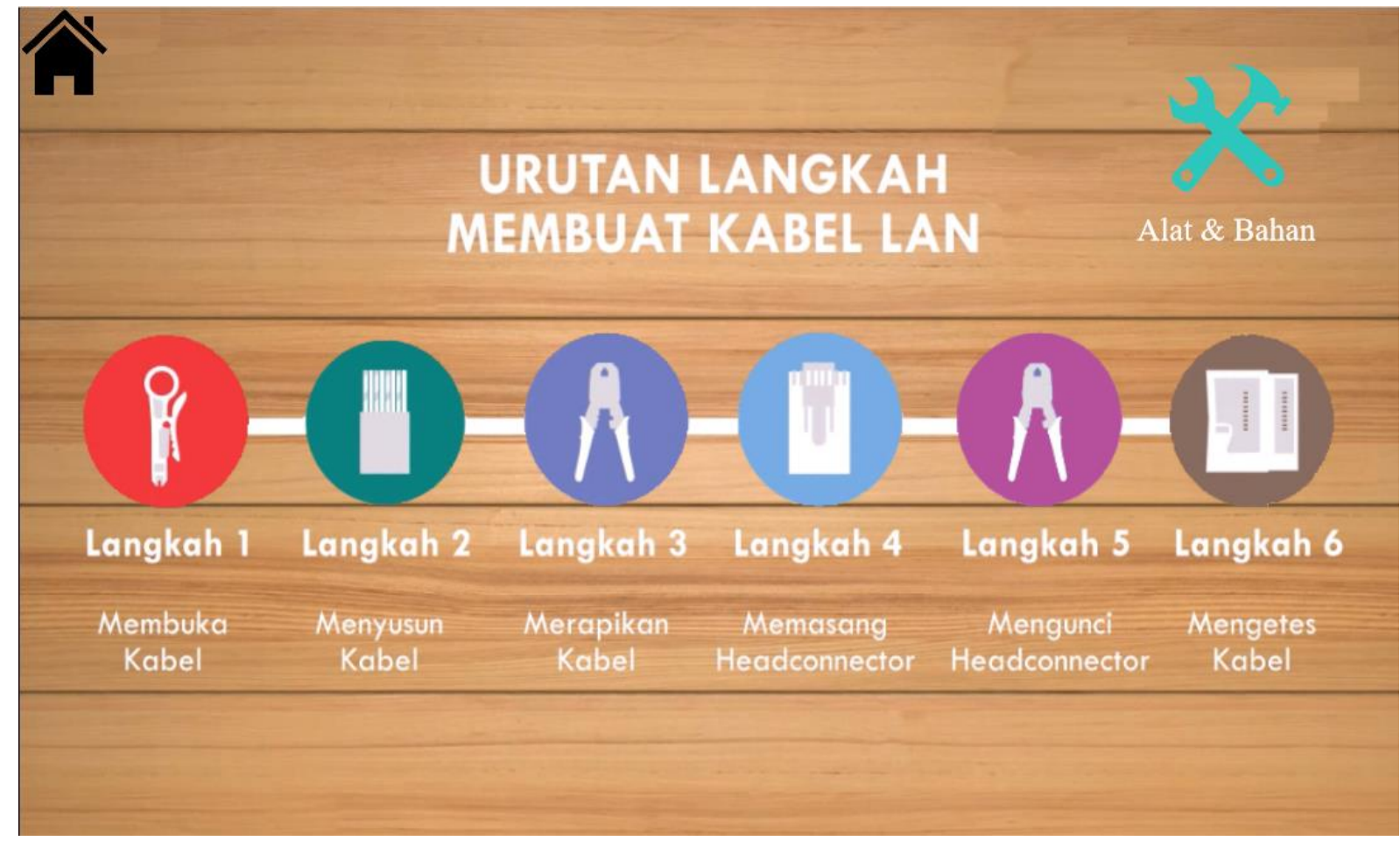

\section{Gambar 5. Antarmuka Urutan praktik Membuat Kabel LAN}

F. Antarmuka menu Alat dan bahan

Antarmuka button masuk ke menu Alat dan bahan untuk membuat kabel LAN serta button kembali ke menu sebelumnya..

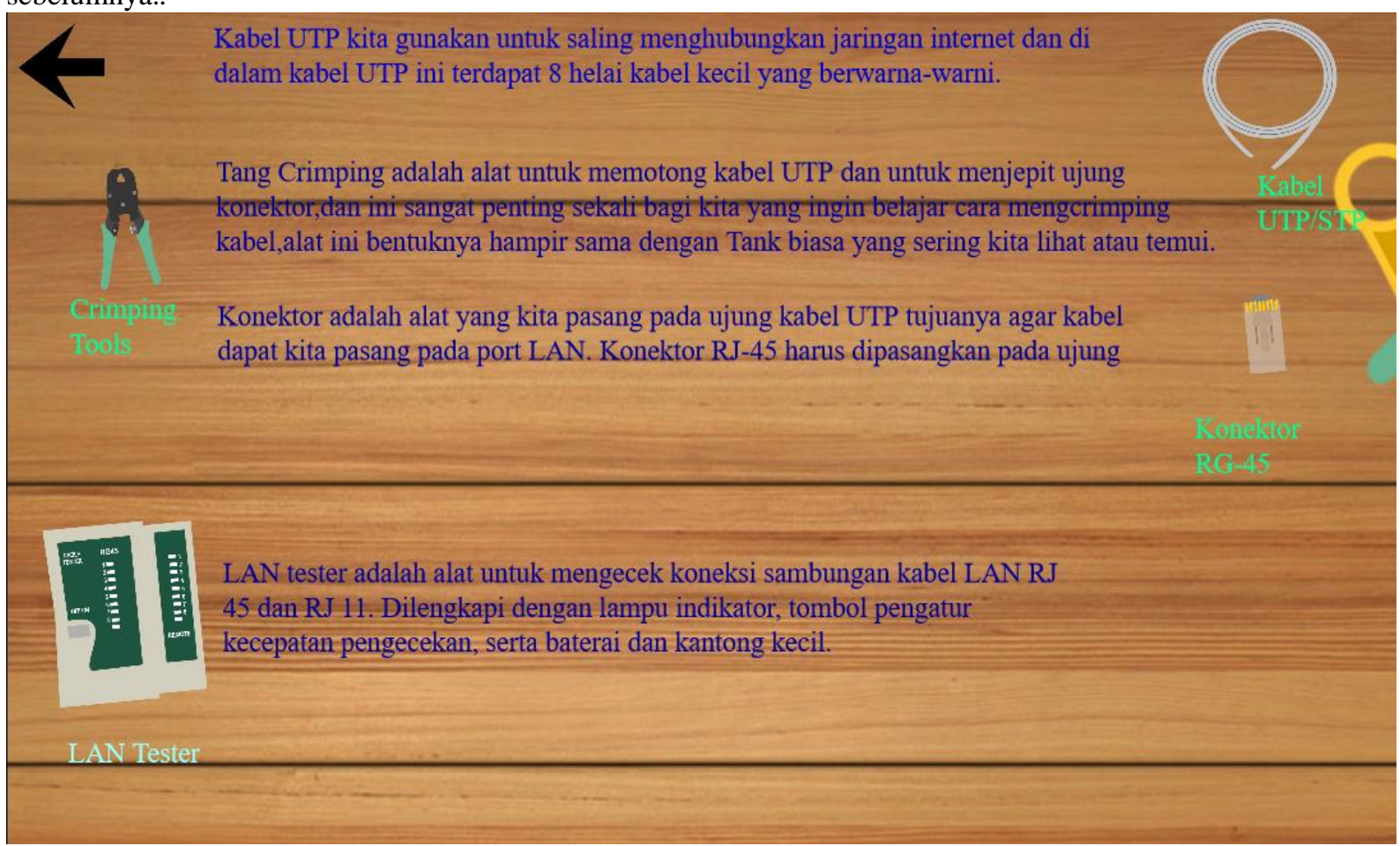

\section{Gambar 5. Antarmuka menu Alat dan bahan}

G. Antarmuka Langkah Pertama Simulasi

Antarmuka halaman langkah pertama simulasi membuat kabel LAN berisi animasi interaktif untuk memotong kabel UTP dengan memutar UTP Stripper. Terdapat button kembali, langkah berikutnya. 


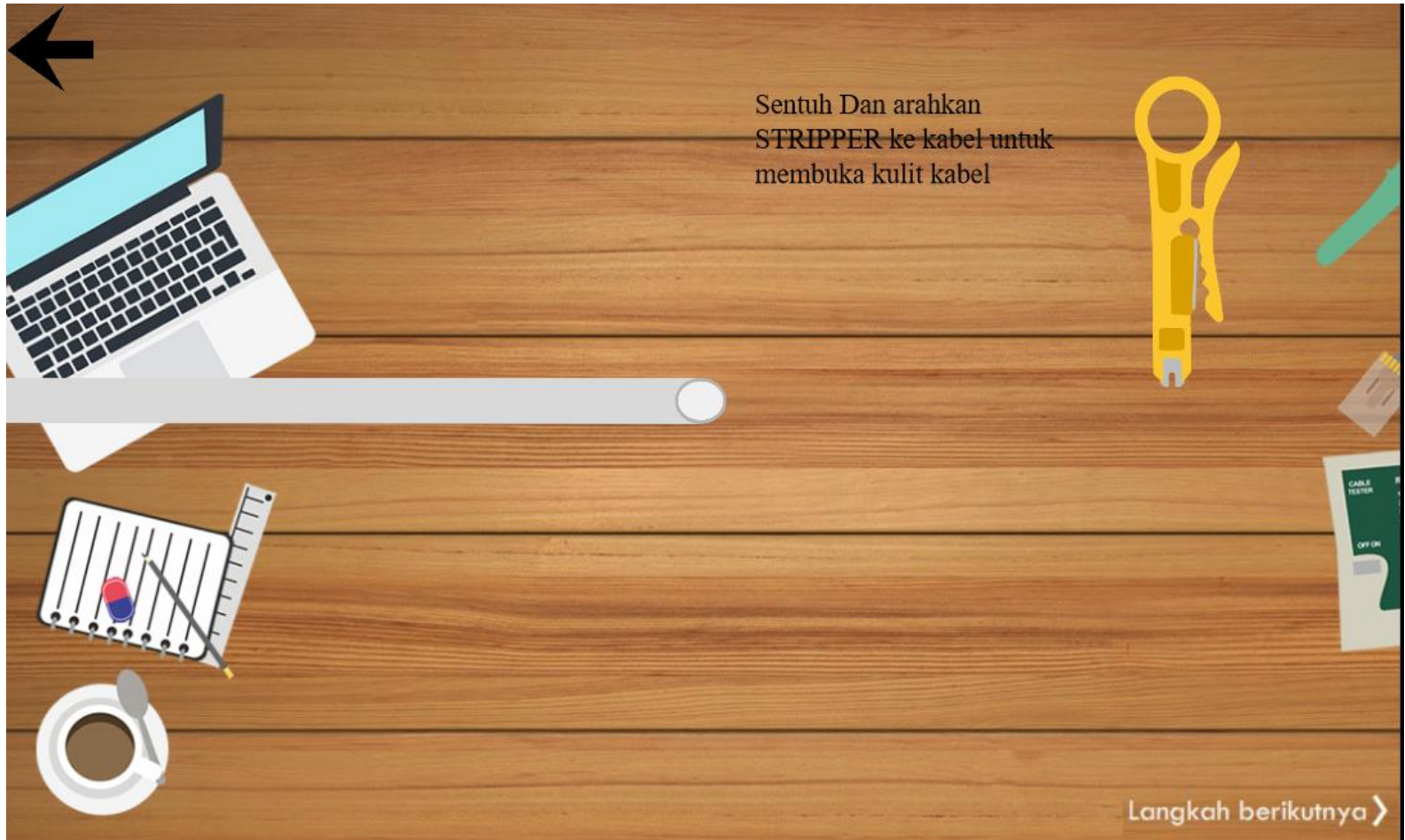

Gambar 7. Rancangan Antarmuka Langkah Pertama Simulasi

3.Tampilan evensheet Construct 2

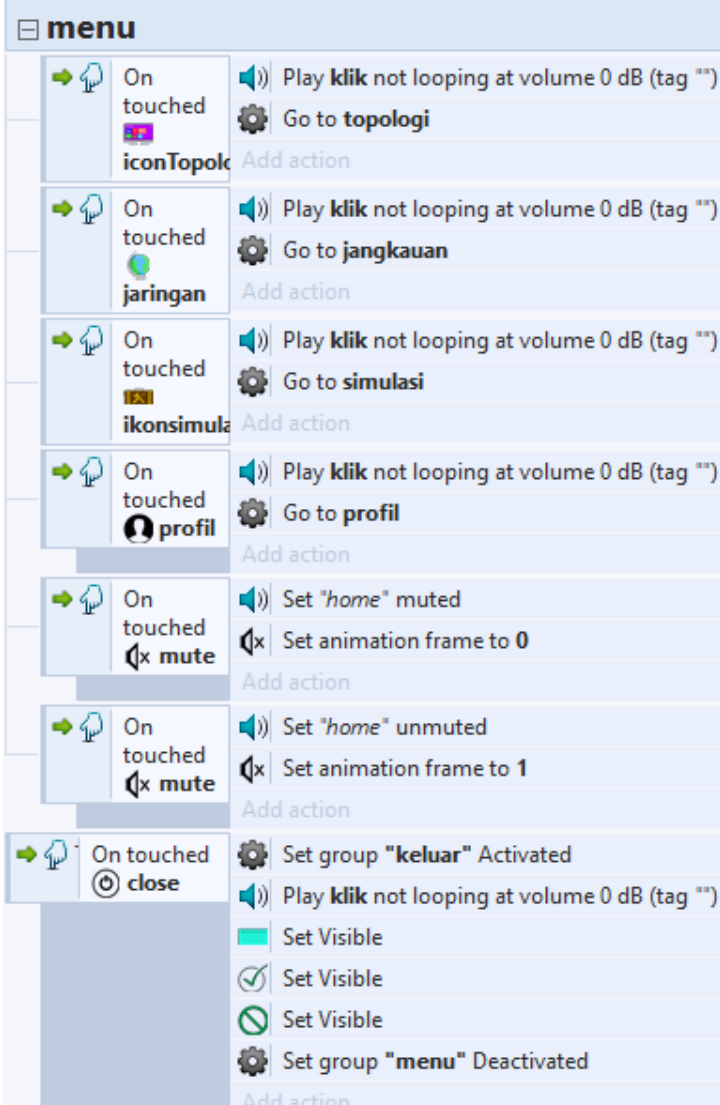

\section{Gambar 8. Tampilan Evensheet dari menu home}

\section{KESIMPULAN}

Berdasarkan hasil penelitian tentang Animasi Interaktif Klasifikasi Jangkauan Dan Topologi Jaringan Komputer Berbasis Android Sebagai Media Belajar dibuat untuk memecahkan permasalahan yang ada dalam kegiatan 
pembelajaran jaringan komputer tentang klasifikasi jangkauan dan topologi serta permasalahan dalam praktik membuat kabel LAN.

\section{REFERENSI}

Armansyah, F., Sulton, S., \& Sulthoni, S. (2019). Multimedia Interaktif Sebagai Media Visualisasi Dasar-Dasar Animasi. Jurnal Kajian Teknologi $224-229$. https://doi.org/10.17977/um038v2i32019p224

Damayanti, D., Akbar, M. F., \& Sulistiani, H. (2020). Game Edukasi Pengenalan Hewan Langka Berbasis Android Menggunakan Construct 2. Jurnal Teknologi Informasi Dan Ilmu Komputer, 7(2), 275. https://doi.org/10.25126/jtiik.2020721671

Haris, A., \& Putra, M. Y. (2020). Animasi Interaktif Pengenalan Anggota Tubuh Menggunakan Bahasa Arab Pada SD-IT Roudhotul Jannah Bekasi. 4(2), 145-154.

Herawati, A., Wahyudi, W., \& Indarini, E. (2018). Pengembangan Media Pembelajaran Bangun Ruang Berbasis Discovery Learning dengan Construct 2 dalam Meningkatkan Kemampuan Pemecahan Masalah Matematika. Jurnal Ilmiah Sekolah Dasar, 2(4), 396. https://doi.org/10.23887/jisd.v2i4.16157

Kusumayanti, D., \& Astuti, C. C. (2021). Android Based E-Module Development on Computer Learning and Basic Networks Class X Tkj Smk Ar-Roudhoh. JICTE (Journal of Information and Computer Technology Education), 5(1), 24-30. https://doi.org/10.21070/jicte.v5i1.1335

Luhulima, D. A., Degeng, I. N. S., \& Ulfa, S. (2017). Pengembangan Video Pembelajaran Karakter Mengampuni Berbasis Animasi Untuk Anak Sekolah Minggu. Jurnal Inovasi Dan Teknologi Pembelajaran, 3(2), 110120.

Maiyana, E. (2018). Pemanfaatan Android Dalam Perancangan Aplikasi Kumpulan Doa. Jurnal Sains Dan Informatika, 4(1), 54-65. https://doi.org/10.22216/jsi.v4i1.3409

Nurhalimah, S. R., Suhartono, S., \& Cahyana, U. (2017). Pengembangan Media Pembelajaran Mobile Learning Berbasis Android pada Materi Sifat Koligatif Larutan. JRPK: Jurnal Riset Pendidikan Kimia, 7(2), 160167. https://doi.org/10.21009/jrpk.072.10

Rosmaidah, I., \& Destiana, H. (2017). Perancangan Animasi Interaktif Belajar Mengenal Huruf Hijaiyah Pada TKQ Al-Khoiriyah. Jurnal Teknik Informatika, ISSN:2442-2436, III(1), 100-105. https://ejournal.bsi.ac.id/ejurnal/index.php/jtk/article/download/1350/1098

Saputra, P. A., \& Retnoningsih, E. (2020). Animasi Interaktif Pengenalan Negara ASEAN Menggunakan Metode Multimedia Development Life Cycle. Journal of Students 'Research in Computer Science, 1(2), 153-164. https://doi.org/10.31599/jsrcs.v1i2.406 